\title{
A RENOVAÇÃO DA GEOGRAFIA: A CONSTRUÇÃO DE UMA TEORIA DE TERRITÓRIO E DE TERRITORIALIDADE NA OBRA DE JEAN GOTTMANN ${ }^{1}$
}

\author{
Marcos Aurelio Saquet \\ Professor da Universidade Estadual do Oeste do Paraná. Pesquisador do CNPq \\ saquetmarcos@hotmail.com
}

\section{Resumo}

O objetivo principal da pesquisa que estamos realizando, nos últimos anos, é compreender as diferentes abordagens e concepções de território e territorialidade, renovadas a partir dos anos 1960-70 até o momento atual. Para tanto, elegemos obras e autores da França, Itália, EUA e Brasil, da geografia e outras ciências sociais, que dão centralidade a esses conceitos. Neste texto, evidenciamos a abordagem crítica e não marxista de Jean Gottmann, autor de grande importância para a geografia em nível internacional, porém pouco conhecido e divulgado no Brasil.

Palavras-chave:Geografia, território, territorialidade.

\begin{abstract}
The main objective of this research that we have accomplishing, in the last years, is to understand the different approaches and conceptions of territory and territoriality, renewed, from the 60 s and 70 s until the current moment. So that we have chosen works and authors from France, Italy, USA and Brazil, from Geography and others socials science, that give centrality to these concepts. On this text, we stand out the critic and not the marxist approach of Jean Gottmann, author of great importance for the Geography worldwide, but not advertised in Brazil.
\end{abstract}

Key-words: Geography, territory, territoriality.

\section{$0 \bigcirc 0$}

\section{INTRODUÇÃO}

Alguns pesquisadores, como Horacio Capel, Paul Claval, Yves Lacoste, Ruy Moreira, Massimo Quaini, Roberto Lobato Corrêa, Giuseppe Dematteis, entre outros, já evidenciaram traços muito importantes e decisivos na construção da geografia moderna e de seus principais desdobramentos ocorridos durante o século XX. Alguns autores estão refletindo sobre a ciência geográfica do início do século XXI como produto histórico e geográfico de longa duração. As abordagens e concepções que se delineiam neste momento histórico contêm, em diferentes países, universidades e grupos de estudos, componentes muito fortes que são conservados, ora das argumentações de Alexander von Humboldt, ora de Friedrich Ratzel, Richard Hartshorne ou de Vidal de La Blache, por exemplo.

Porém, a geografia de síntese ou a geografia das particularidades ou ambas misturadas assumem novos significados, incorporando novos elementos na tentativa constante de explicação geográfica do mundo. Assumem novas leituras, sobretudo a partir dos anos 1940-60, com o reconhecimento e a incorporação de princípios epistemológicos que tentam superar as descrições predominantes até aquele período. Forjam-se, num primeiro momento, argumentações, na Inglaterra, na Suécia e nos EUA, que valorizam e destacam determinadas técnicas matemáticas e estatísticas. Ao mesmo tempo, e com maior evidência, a partir dos anos 1970, elaboram-se novas bases epistemológicas para a geografia, centradas em princípios filosóficos do materialismo histórico e dialético.

Paul Claval, em sua clássica obra sobre a história da geografia, intitulada Evolución de la Geografia Humana, explicita esse movimento de renovação constante do pensamento geográfico, envolvendo, na França, país em que a chamada geografia regional teve centralidade na produção acadêmica, o método histórico e o método sistêmico e, nos EUA, a geografia cultural. Anteriormente, destacavam-se elabora- 
ções importantes de P. Kropotkin e E. Reclus que se posicionaram contra a estrutura de poder dominante durante o período de suas vidas, adotando princípios em favor de reformas sociais radicais e de grupos sociais dominados. Eles tiveram uma prática política denominada libertária, em razão de postulados e ações efetivadas com determinados grupos sociais. Enfim, há distintas concepções e grupos de pesquisadores que se ligam e se complementam em alguns aspectos e momentos históricos.

Nos anos 1970, entre os estudos que evidenciam o conceito de território destacam-se alguns de Gilles Deleuze e Félix Guattari (filosofia e psicanálise), Giuseppe Dematteis, Massimo Quaini, Edward Soja, Arnaldo Bagnasco (sociologia), Paul Claval, Francesco Indovina (economia), Donatela Calabi (economia), Alberto Magnaghi (urbanismo), Umberto Eco (filosofia) e Claude Raffestin, entre outros talvez menos conhecidos entre nós da geografia. Um dos pesquisadores que se destacam é justamente Jean Gottmann, figura central na renovação da geografia a partir dos anos 1940-50 e na redescoberta do conceito de território entendido de maneira crítica.

É desse movimento que tratamos neste texto, revelando mais detidamente alguns traços das pesquisas feitas nos últimos anos e centradas no desafio de apreender os fatores da renovação da ciência geográfica a partir dos anos 1960-70 e as principais concepções teórico-metodológicas elaboradas e as abordagens renovadas dos conceitos de território e territorialidade.

Dito de outra maneira, nosso objetivo principal é compreender os conceitos de território e territorialidade, evidenciando abordagens, concepções e os seus elementos constituintes considerados por pesquisadores de referência internacional, a partir dos anos 1960-70, numa problemática claramente epistemológica muito bem enunciada por Raffestin e Turco (1989).

Com isso, fica claro ao leitor que não estamos estudando todos os autores nem todas as escolas com certo destaque na geografia. Definimos, até o momento, autores e obras das literaturas francesa, italiana e brasileira, com relevância e destaque em nível internacional e que dêem centralidade aos conceitos de território e/ou territorialidade, como já revelamos em Saquet (2006 e 2007).

Esses são nossos recortes principais; ao mesmo tempo, estamos fazendo um esforço para contribuir na elaboração de uma argumentação teórico-metodológica que considere a relação tempo-espaço-territórioterritorialidade num movimento do pensamento para compreender o movimento do e no território e na e da territorialidade cotidiana. Aqui, evidenciamos alguns aspectos sobre a metodologia adotada na pesquisa e elementos do pensamento de Jean Gottmann que consideramos basilares por seu pioneirismo e pela coerência de uma abordagem que denominamos de (i)material, ou seja, material e imaterial simultaneamente, numa concepção crítica não marxista muito atual. Este texto é parte dos resultados obtidos até o momento na pesquisa.

Essa observação é fundamental, considerando a importância de apreender o movimento em estudos territoriais como produto de determinações (i)materiais, ou seja, de forças econômicas, políticas e culturais que condicionam os saltos quantitativos e qualitativos na dinâmica socioespacial. A matéria e a idéia estão em unidade e movimento constante, no qual há superações, territorialidades e temporalidades, ambas históricas e coexistentes. No entanto, este entendimento não é consensual nem foi historicamente reconhecido nas ciências sociais.

Por fim, é importante destacar que, no decorrer dos estudos, realizamos pesquisa bibliográfica, fichamentos, colóquios no âmbito do Grupo de Estudos Territoriais (Geterr) que coordenamos e com pesquisadores estrangeiros, organizamos um seminário, participamos de eventos científicos e redigimos dois relatórios (um para a Capes e outro para a Unioeste). Parte considerável da pesquisa sobre a abordagem de Jean Gottmann foi realizada na Itália, em 2006, durante o estágio de pós-doutorado que fizemos em Turim com bolsa da Capes. Ali, foi fundamental o debate feito com alguns professores doutores: a) Luca

Revista da ANPEGE v. 5, 2009 
Muscarà, da Universidade de Molise, grande estudioso da vida e obra de Jean Gottmann; b) Giuseppe Dematteis, do Politécnico e Universidade de Turim; c) Massimo Quaini, da Universidade de Gênova, aos quais agradecemos a atenção dedicada às nossas pesquisas.

\section{A CONSTRUÇÃO DO CONHECIMENTO E DO PENSAMENTO}

Como referencial teórico basilar, entendemos que a construção do conhecimento é cumulativa, histórica e relacional. Como ensinam Massimo Quaini, já citado, e outros autores brasileiros como Roberto Lobato Corrêa, Ruy Moreira, Antonio Carlos Robert Moraes, Eliseu Sposito e Rogério Haesbaert (cada um com seus objetivos específicos e com sua abordagem), a geografia (e outras ciências sociais) é organizada e reconstruída historicamente na tentativa constante de explicar os processos sociais e espaciais.

Há um esforço considerável de vários pesquisadores para gerar uma interpretação constante e coerente dos processos do mundo. Isso resultou numa renovação continuada do pensamento e do conhecimento na geografia e em outras ciências sociais. Estamos entendendo que a produção do conhecimento, vista como relacional e histórica, dá-se numa relação espaço-tempo, condicionando e traduzindo-se, nesse caso, em diferentes abordagens e concepções do território e da territorialidade construídas em diferentes momentos e lugares.

Uma de nossas principais referências para realizar a pesquisa em questão foi o geógrafo italiano Massimo Quaini (2003 e 2005), que oferece alguns procedimentos basilares para uma pesquisa dessa natureza. São eles: selecionar e utilizar as obras produzidas com bastante tempo e dedicação; narrar com reflexão (a história da geografia), mais como uma problemática do que como uma solução; apreender a complexidade de relações sociais existentes entre pesquisadores, grupos de estudos e universidades; identificar as categorias utilizadas, reconstruindo caminhos percorridos e entrevistar autores sobre sua história de vida e produção intelectual. Consideramos fundamental identificar as principais referências utilizadas por cada autor em suas argumentações bem como características do contexto social de sua vida e produção intelectual. As entrevistas são, de fato, muito importantes, pois possibilitam a apreensão de detalhes e sutilezas que não transparecem nos textos tanto teórico-metodológicos e conceituais como biográficos. Foi nesse sentido que, no decorrer da pesquisa, entrevistamos os professores Giuseppe Dematteis, Luca Muscarà, Massimo Quaini e Claude Raffestin.

É uma abordagem, a que estamos fazendo, de aspectos do pensamento geográfico, centrada no movimento histórico e em relações multiescalares efetivadas entre diferentes pesquisadores em distintos lugares, com múltiplas determinações. Compreender a constituição da denominada geografia crítica e de novas concepções do território e da territorialidade significa entender, necessariamente, os fatores históricos condicionantes, isto é, as mudanças sociais e espaciais que se processavam na economia, na política e na cultura como processos relacionais que determinaram a renovação dessa ciência; suas principais características, tais como temas, conceitos, recortes, objetivos etc. bem como conflitos e contradições internas à ciência geográfica. A produção do conhecimento e do pensamento é, simultaneamente, processual e relacional e extrapola os "limites" de cada ciência.

Precisamos ter um movimento em nosso pensamento para compreender o movimento do pensamento e de produção da ciência. O pensamento que estudamos precisa expressar-se em nosso pensamento, falas e textos. O movimento do pensamento em sensações, percepções, leituras, reflexões é um aspecto do abstrato e, ao mesmo tempo, tem objetividade como um processo de nossa vida cotidiana, inerente aos processos territoriais. Há pensamento em movimento sobre o movimento do pensamento, da vida e seus múltiplos conteúdos. 
No real e em nosso pensamento (na unidade real-pensamento-real), o movimento está presente como componente, determinante e resultado. Todos vivemos em movimento de idéias, construções, ações, reações, encontros e desencontros, enfim, em múltiplas relações históricas e geográficas. O movimento é resultado e condicionante de determinações territoriais (i)materiais; de contradições sociais; das forças econômicas, políticas e culturais que condicionam a vida, o pensamento.

A matéria e a idéia, em unidade, estão em constante movimento, havendo neste superações e interações. As relações e conflitos impulsionam o movimento, a superação, que é fugaz, fluida, efêmera. Por isso, o movimento processual-relacional é difícil de ser apreendido e pode ser compreendido parcialmente, em fragmentos e traços de unidade, conforme ensina Jean Gottmann.

\section{O HÍBRIDO DE JEAN GOTTMANN}

A obra de Jean Gottmann expressa muito bem o movimento do pensamento, da vida dele mesmo e de sua família, como sujeito excluído e condicionado a migrar, e como pesquisador que elabora uma abordagem híbrida, construída durante seus 60 anos de produção intelectual, especialmente na França e nos EUA. É pouco conhecido no Brasil, provavelmente, pela não tradução de seus textos para a língua portuguesa.

Jean Gottmann é um dos autores responsáveis por um salto qualitativo referente às concepções renovadas de território e da própria geografia, a partir de sua formação basilar na escola francesa, de derivação vidaliana, através de Emmanuel de Martonne, Jean Brunhes, Albert Demangeon, Raoul Blanchard, Camille Vallaux e Julien Sion.

Membro de uma família de hebreus russos, foi obrigado a migrar, quando criança, em virtude da revolução de 1917, passando por diferentes países até seus pais instalarem-se na França. Durante a II Guerra Mundial, em 1941, teve que migrar para os EUA. Na França e nos EUA, vive e acompanha mudanças profundas que acontecem na sociedade, transformações econômicas (internacionalização do capital), geopolíticas (Guerra Fria) e culturais (etnocentrismos...), processos que influenciam diretamente na sua elaboração teórico-metodológica - consoante tentamos deixar claro no decorrer deste texto - juntamente com desdobramentos da geografia, do direito internacional, da economia e de outras ciências, que ocorrem no novo contexto emergente a partir da II Guerra Mundial. Jean Gottmann não incorpora efetiva e sistematicamente a geografia vidaliana nem a hartshorniana e princípios da nova geografia, e foi por isso, provavelmente, que foi envolvido em conflitos, negligenciado e não conseguiu se firmar academicamente na França.

Com sua transferência aos EUA, Jean Gottmann teve uma importante relação com Isaiah Bowman na universidade Johns Hopkins. Ele fez vários estudos regionais sobre a Rússia, França, Alemanha, Síria, Líbano e EUA, experimentando e evidenciando aspectos relativos à pesquisa científica em geografia humana. Uma de suas principais obras é La politique des États et leur Géographie, publicada em 1952, ampliando consideravelmente o conceito de território, em relação à abordagem feita por Friedrich Ratzel, para além do Estado-nação ou suporte de ações dos homens. Metodologicamente, Jean Gottmann deixa um legado muito importante para a abordagem territorial e, de forma mais geral, para a geografia, ensinando sobre a elaboração de analogias e generalizações a partir da análise diacrônica de variações espaciais, especialmente de geografia política e urbana.

Felizmente, entre tantas contribuições importantes, legou-nos uma síntese de sua concepção de geografia (humana), num texto publicado em 1947. Após uma crítica à definição de gêneros de vida, formulada por Vidal de La Blache, Jean Gottmann transcende produções disciplinares de geografia e incorpora noções 
importantes como a de frentes de colonização ou franjas pioneiras, inicialmente elaborada por Isaiah Bowman, e as de circulação e fluidez, garimpadas em estudos de economia. Gottmann combina tais noções com as de povoamento e habitat, que já tinham certa tradição de uso na geografia. E é com essa combinação entre elementos areais e reticulares que Jean Gottmann consegue avançar na sua reflexão e argumentação, pois incorpora novos componentes que favorecem o rompimento com a geografia regional francesa predominante em sua época, na qual alguns autores propugnavam em favor de abordagens eminentemente areais e descritivas. Fluidez e circulação de pessoas e mercadorias são noções e processos fundamentais que estão na base da divisão e organização espacial, substantivando territórios a partir da dominação econômica e política. A fluidez e a circulação favorecem o fortalecimento dos mercados, a concorrência, os contatos e as transformações, acirrando conflitos entre os agentes econômicos e o Estado.

É a partir dessa complexa relação que Jean Gottmann, criativamente, combina proteção e segurança com oportunidades e possibilidades, elementos que o induzem a elaborar, mais adiante, a noção de iconografia como um mecanismo para proteção e segurança diante dos avanços da circulação e conseqüente desestabilização.

Outra noção fundamental, trabalhada por Gottmann (1947), é o reconhecimento e a valorização do que denomina de fatores psicológicos, como mecanismos de forte influência no consumo de mercadorias e, assim, na circulação. O uso de gravata, exemplifica, passa de um capricho a ter o significado de mercadoria, justamente em razão de influências do mercado através da criação simbólica de uma nova necessidade: o uso de gravatas como um componente estético e da moda. O fator psicológico é um determinante fundamental do consumo. Ele associa, dessa maneira, na geografia, processos materiais e imateriais, areais e reticulares como determinantes e caracterizadores do território, argumentando contra o que denomina de materialismo geográfico muito simples e em favor de uma concepção híbrida e renovada para sua época e com contribuições importantes para os tempos atuais.

Ao descobrir a filosofia de Henri Bérgson, Gottmann atribui uma dimensão relacional à análise geográfica. Elabora, para a explicação geográfica, uma abordagem histórica e relacional, com elementos (i)materiais. E são os fatores espirituais, por exemplo, que conduzem Gottmann (1950) a caracterizar regiões culturais na Europa e ao conceito de iconografia; esta pode conter uma combinação de elementos culturais, econômicos e políticos, todos constituídos historicamente.

No decorrer de suas observações e discussões - pesquisas - , ele acrescenta o componente ambiente (contexto físico), indicando uma abordagem renovada e múltipla em geografia. No entanto, é um elemento que permanece secundário em sua argumentação, conforme notamos em sua obra, de 1952, em que apresenta uma abordagem que transita entre a geografia política e a geografia cultural, destacando a divisão política do espaço e a diferenciação cultural em escala regional, num misto que evidencia particularismos e sínteses mais gerais de alguns países a partir de duas forças principais: a circulação e as iconografias. Para Gottmann, sucintamente, a circulação favorece a abertura, a fluidez e as iconografias, a resistência. A efetivação de iconografias pode gerar situações de estabilidade e segurança (Calogero Muscarà, 2003a), justamente o contrário da circulação, que é inerente à mudança social e tem na cidade seu locus principal.

Nesse sentido, é a partir das iconografias que se formam, conforme Gottmann (1952), os regionalismos e, possivelmente, novas nações. Já a circulação corresponde à força motriz da mudança, através de fluxos. A circulação facilitada, por exemplo, pela construção de estradas é determinante na organização do espaço, definindo redes que interligam diferentes centros. As redes são fundamentais na formação de cada território e na definição das territorialidades de cada grupo social juntamente com as iconografias. 
O princípio de fluidez é central em sua concepção como circulação, movimento perpétuo que se decompõe em outros movimentos particulares, ligando diferentes países e cidades. Circulação de homens, mercadorias e idéias que envolve edificações (estações ferroviárias, portos, estradas, aeroportos...) e o fator psicológico como principal determinante do consumo e da mobilidade de indivíduos.

O fator espiritual também é central em sua proposta; é a base para o dinamismo da geografia humana (econômica, política e social). A combinação entre componentes materiais e espirituais da vida estabelece cruzamentos, lugares, um sistema de relações e de redes. E é a partir dessas considerações que Gottmann (1952) explicita sua abordagem crítica e não marxista, tentando conciliar idéia e matéria como uma forma coerente de explicação da realidade, heuristicamente.

É assim que Muscarà (2005a) denomina a abordagem e concepção de Jean Gottmann: heurística, em virtude justamente da conciliação do movimento tanto na circulação como na iconografia, a partir da teoria dos conflitos antagônicos desenvolvida por Henri Bérgson. Gottmann tem três referências fundamentais: Isaiah Bowman, Albert Demangeon e Henri Bérgson, articulando, assim, elementos das escolas francesa e norte-americana como os conceitos de tecido, nó, dinâmica social e frentes de colonização.

Segundo Gottmann (1952, p.199-200):

(...) as atitudes regionais não são tanto ditadas pela posição dos Estados em certo continente como pelos sistemas políticos e econômicos presentes e passados dos quais os Estados fazem parte. Pode-se dizer que a posição em uma parte do mundo faz parte da iconografia regional, mas o fator religioso ou cultural, o ressentimento nos confrontos dos antigos colonizadores ou os acordos de paz nos conflitos das nações em problemas similares, são bem mais potentes nessa iconografia.

E mais:

(...) A circulação permite organizar o espaço e é no decorrer deste processo que o espaço se diferencia. Os mecanismos deste processo se desmontam facilmente, seguindo as grandes vias de circulação e formando cruzamentos onde estas vias se encontram. A circulação dos homens e de seus produtos é a grande dinâmica humana que torna apaixonante os estudos sobre população e que renova constantemente a geografia (GOTTMANN, 1952, p. 214).

Jean Gottmann chama a atenção para a importância da iconografia como processo que está na gênese da unidade de certa comunidade. Ela é fator da compartimentação e de unidade, defesa, organização social e interage com a circulação. Para Luca Muscarà (2003 e 2003a), a circulação favorece a abertura de espaços, enquanto as iconografias são definidas como símbolos religiosos e políticos que funcionam como um sistema de resistência à circulação e à mudança e são controladas pelo poder político. Tanto a circulação como as iconografias ocorrem em nível supranacional e em regiões internas dos Estados ou impérios ou cidades fortificadas.

Os cruzamentos/entroncamentos que são estabelecidos historicamente entre diferentes caminhos/estradas significam a ligação e interação entre circulação e iconografia. Há unidade dada pelo movimento de circulação. É nos cruzamentos que se dá, por exemplo, a edificação de monumentos religiosos e o encontro de diferentes vias de circulação e comunicação. Processo que foi instituído historicamente, primeiro pelos indígenas através de suas iconografias e, posteriormente, pelas sociedades da antigüidade, pelas sociedades imperiais e feudais até as edificações e relações definidas pelo modo capitalista de produção, no qual a circulação assume centralidade na reprodução do capital.

Os cruzamentos de vias são explorados tanto para fins mercantis como militares, para policiamento, controle e aceleração do movimento de rotação de mercadorias. Por isso, assumem cada vez mais impor- 
tância na organização de cada território, consoante demonstrara Gottmann (1973/2005). Os cruzamentos e vias formam sempre novas redes de circulação e comunicação, interligando lugares, pessoas e territórios.

A compartimentação política do mundo, para Gottmann (1973/1975/2005), ocorre centrada em dois grandes processos, de diferenciação cultural e articulação mercantil, nos quais se efetivam fatores materiais e psicológicos que influenciam diretamente na organização de cada território. Esta organização é fruto das relações sociais, das iconografias e da circulação. Por isto, ele entende o conceito de território formado por componentes materiais e psicológicos, como um expediente psicossomático que influencia tanto na proteção e refúgio, a partir da iconografia estabelecida, como na oportunidade e trampolim, derivados da circulação.

Sucintamente, o território é compreendido, conforme mencionamos em Saquet (2007), como lugar de proteção, segurança e oportunidade. É produto de relações sociais, econômicas, políticas e culturais, ou seja, de territorialidades historicamente determinadas, num híbrido entre generalizações e particularidades, materialidades e imaterialidades, fluidez e estabilidade. Jean Gottmann concilia coerentemente, em suas pesquisas, traços da relação espaço-tempo para explicar dinâmicas sociais e territoriais ocorridas na França, nos EUA e noutros países. A territorialidade, assim, corresponde às relações simbólico-culturais, políticas e mercantis efetuadas pelas pessoas.

Gottmann (1973/2005) evidencia, em sua abordagem, o uso geopolítico e econômico do espaço e a constituição histórica do Estado desestabilizada pelo acirramento da circulação. O território é entendido como área/repartição controlada através de uma jurisdição específica na geopolítica mundial e, ao mesmo tempo, significa urbanização e fluxos, interdependência, complementaridade, processos que fazem parte do avanço da circulação, o que confere um caráter cada vez mais relacional à sua teorização.

Para esse autor, o conceito de território não pode ser classificado como um fenômeno inanimado, mas precisa ser compreendido como uma área onde há um elemento de centralidade, que pode ser uma autoridade exercendo soberania sobre as pessoas ou o uso (social) de um lugar. O controle é um atributo específico dos homens e está presente na constituição do território: este significa uma expressão geográfica da dominação social em certa área. O controle significa, ao mesmo tempo, relações de poder realizadas entre os homens em áreas compartimentadas ou entre diferentes áreas: são as territorialidades, que correspondem aos comportamentos culturais, geopolíticos, econômicos e psicológicos ou, dito de outra maneira, ao exercício de influência, controle e pertencimento.

Detalhando nosso olhar e compreensão, notamos que, para Jean Gottmann, o território significa uma construção social, através da qual os grupos sociais repartem o mundo politicamente. A soberania é um potente fator que influencia na divisão política enquanto os progressos tecnológicos favorecem, gradualmente, a mobilidade das pessoas e a circulação de mercadorias. As forças políticas e econômicas determinam a repartição (em frações) e o controle do espaço, juntamente com fatores naturais e culturais.

A organização do espaço, como território, dá-se a partir das condições sociais e naturais para atender a duas funções principais: segurança e oportunidade, conforme já mencionamos; ambas exigem a organização interna do território através da jurisdição e soberania do Estado bem como relações externas, diplomáticas e econômicas (mercado e progresso tecnológico). O território é uma entidade material, resultado das características psicológicas (atitudes ...) de um grupo social, contendo a contradição basilar entre segurança e oportunidade, controle e descontrole, regulação política e uso econômico como espaço de competição, especialização, fluidez e urbanização.

Em seus dois textos publicados em 1980, na obra intitulada Centre and periphery - spatial variation in politics, Jean Gottmann evidencia claramente a centralidade dada aos processos de circulação na defi- 
nição dos compartimentos político-administrativos e que ocorre entre os países do centro e da periferia, denominações que ainda julgava relevantes naquele momento de sua intelectualidade, provavelmente, por influência do geógrafo italiano Calogero Muscarà (1967 e 1976). Pelo que conseguimos identificar durante as pesquisas feitas na Itália, seu ótimo nível de amizade e trabalho com Calogero Muscarà também influenciou diretamente suas pesquisas, elaborações teóricas e publicações feitas na Itália.

Em uma de suas principais obras, Muscarà (1967) considera a processualidade histórica e as relações sociais, princípios metodológicos presentes na abordagem de Jean Gottmann. Parece que há uma influência mútua entre ambos, pois Calògero Muscarà também contribui para construir uma concepção não marxista de geografia: compreende temas como o desenvolvimento italiano, a industrialização e a urbanização como problemas territoriais resultantes do processo histórico e compostos por desigualdades e articulações (relações internas e externas a cada território, horizontais e verticais). As regiões correspondem a territórios desigualmente desenvolvidos sobretudo em virtude de fatores econômicos e políticos, similar ao que argumenta Gottmann (1980).

Nesta obra, identificamos traços centrais de sua argumentação teórico-metodológica dos anos 1970, porém, com a manutenção de elementos elaborados desde o final da década de 1940, especialmente no seu La politique des États et leur Géographie (1952). Há conciliação entre processos políticos e econômicos, ou seja, entre a divisão e controle de certas áreas e o acirramento da circulação de mercadorias e pessoas. O espaço geográfico é considerado resultado das atividades humanas, que são diversificadas e responsáveis pela variação espacial, isto é, pelas desigualdades. A organização do espaço envolve processos políticos e econômicos, com limites e sua transposição: há articulação entre os lugares, no caso, entre os países do centro e da periferia, formando um sistema complexo. Tal articulação é produto das tecnologias modernas, que provocam instabilidade e constante interferência na atuação do Estado. Isso gera o que denomina de novos sistemas de coordenadas políticas e econômicas, redimensionando as ações de centralidade.

As grandes cidades, por exemplo, exercem novas centralidades em nível nacional e internacional. Há uma ordem da fluidez que envolve a periferia: esta assume novas formas de centralidade em virtude das inovações tecnológicas e dos papéis exercidos pelas grandes cidades (Roma, Paris, Londres, Moscou, Nova Yorque, Tóquio, México...). Estas são centros de difusão de informações, inseridos num contexto de revolução permanente, como aparece também em seu texto de 1980a: o espaço é organizado e reorganizado constantemente, sobretudo em razão de fatores econômicos e políticos, processo no qual a urbanização exerce papel central como demonstrara na Megalópoles (1961).

A aceleração das ações humanas é central na reorganização do espaço, aumentando a interdependência entre países e empresas. As relações são múltiplas e substantivam instabilidade e fluidez. São duas palavras e processos da ordem mundial que se fortalecia nos anos 1970 e consolidava-se a partir da década de 1980, no entanto, não eliminava a estabilidade de dinâmicas políticas e identitárias já cristalizadas. A centralidade é política, econômica e cultural, ou seja, múltipla, característica da sua concepção de geografia, das redes e do território. A aceleração e expansão da circulação de pessoas e mercadorias entre os países são expressões da internacionalização, juntamente com a criação de organismos políticos e financeiros a partir da II Guerra Mundial, que dão novos significados ao território, com novas contradições e conflitos.

Enfim, Jean Gottmann elabora uma teorização crítica e não marxista de geografia e do território, indicando uma abordagem múltipla que reconhece as dimensões sociais do território (economia, política e cultura) e o ambiente natural. Dá ênfase ao controle do Estado, às iconografias e ao movimento realizado por meio da circulação e das redes urbanas, que denomina de fluidez moderna nas obras de 1980, 
1980a e 1991. É uma abordagem areal e reticular muito atual: o território é uma síntese entre dominação política-regulação e circulação-fluidez dos processos econômicos, envolvendo o fenômeno psicológico. E todos esses elementos em conjunto significam, sem dúvidas, um salto qualitativo muito importante para a geografia efetivada na França, nos EUA, na Suíça, na Itália, no Brasil e noutros países, produção intelectual que precisa ser revista, melhor estudada e valorizada em virtude de sua amplitude e coerência com a territorialização de processos geopolíticos, culturais e econômicos.

\section{CONSIDERAÇÕES FINAIS}

$\mathrm{Na}$ argumentação de Jean Gottmann, estão muito claros elementos que carcterizam uma abordagem histórica, relacional e (i)material de geografia e do território. É uma concepção centrada na apreensão de aspectos do movimento, tanto na configuração política do mundo como através da constituição histórica de diferentes iconografias e, sobretudo, através da circulação dos homens, idéias e mercadorias. Ele concilia princípios de estabilidade e de movimento, de materialidade e de imaterialidade da vida dos grupos sociais.

O território contém uma espacialidade concreta e nexos entre população, política e ambiente: a unidade é dada pela soberania (relação de uso do espaço consolidada e definida por um grupo de pessoas politicamente organizadas) e, assim, significa também distinção e separação conjugadas à circulação que define o caráter de interdependência, complementaridade e fluidez. No mundo atual há uma nova ordem, plural, de territórios, relações e redes definidas pelas inovações científicas e tecnológicas. As relações sociais correspondem às territorialidades, internas e externas a cada país e grupo social, caracterizadas pelas atitudes psicológicas e pela apropriação em cada habitat com vistas à conquista de segurança, oportunidade e felicidade.

Dessa forma, podemos pensar na combinação de alguns elementos, que podem subsidiar a elaboração de uma abordagem territorial, nosso foco de pesquisa, como a regionalização/divisão do espaço, as relações de poder, os processos culturais de iconografia e identidade, os fluxos e as redes de circulação e comunicação. A base filosófica pode ser a elaborada por Jean Gottmann ou mesmo a materialista e dialética com ênfase para processos econômicos sem desconsiderar elementos políticos e culturais. É uma questão de método, problemática de estudos, objetivos e propósitos de cada pesquisador que precisa ser abstraída e elaborada detidamente.

Nesse sentido, segundo descrevemos em Saquet (2006 e 2007), o território e as territorialidades são entendidas como resultado e condição do movimento, envolvendo a materialização espacial da sociedade e a dinâmica da natureza exterior ao homem. Território e territorialidades condicionam-se: a construção do território é estabelecida pelas territorialidades que são, ao mesmo tempo, influenciadas pelo território onde há unidade e diversidade determinadas em cada relação tempo-espaço. Conjugam-se materialidade e imaterialidade de formas e relações sociais, identidade e movimento, mudanças e permanências, controle e desregulação no tempo e no espaço.

O território significa materialidade e imaterialidade ao mesmo tempo, não é formado apenas por formas nem apenas por relações sociais: as próprias relações são materiais e imateriais, mudam e permanecem na vida cotidiana. Há uma unidade concreto-abstrata no e do território e na e da territorialidade humana, que precisa ser abstraída constantemente como fez Jean Gottmann e fizeram tantos outros pesquisadores que auxiliam a pensar e apreender os processos territoriais na forma área-rede, rede-rede ou territóriorede-lugar evidenciando os processos econômicos, políticos e culturais ao mesmo tempo e em suas múltiplas formas de territorialização. 


\section{NOTAS}

(1) Nosso projeto de pesquisa conta, além do apoio do Cnpq, com financiamento complementar da Fundação Araucária (Edital Jovens Pesquisadores, 2006).

\section{REFERENCIAS BIBLIOGRÁFICAS}

CLAVAL, Paul. Evolución de la Geografía Humana. Barcelona: Oikos-tau, 1974.

GOTTMANN, Jean. De la méthode d'analyse en géographie humaine. Bulletin de la Societé de Géographie, Paris, n.301, 1947, p.1-12.

GOTTMANN, Jean. Sul metodo di analisi in geografia umana (1947), tradução de Luca Muscarà, Venezia, 1996. (mimeo).

GOTTMANN, Jean. A Geography of Europe. New York: Henry Holt, IX, 1950.

GOTTMANN, Jean. La politique des États et leur Géographie. Paris: Armand Colin, 1952.

GOTTMANN, Jean. The political partitioning of Our World: an attempt at Analysis, World politics, IV, 1952a, p.512-519.

GOTTMANN, Jean. Megalopolis. The urbanized northeastern seabord of the United States. New York: The Twentieth Century Fund, 1961.

GOTTMANN, Jean. The significance of territory. Charlottesville: University Press of Virginia, 1973.

GOTTMANN, Jean. The evolution of the concept of territory. Social Science Information, 14 (3-4), 1975, p.29-47.

GOTTMANN, Jean. Confronting centre and periphery. In: GOTTMANN, J. (Org.). Centre and periphery - spatial variation in politics. Beverly Hills and London: Sage Publications, 1980. p.11-25.

GOTTMANN, Jean. Organizing and reorganizing space. In: GOTTMANN, J. (Org.). Centre and periphery - spatial variation in politics. Beverly Hills and London: Sage Publications, 1980a. p.217-224.

GOTTMANN, Jean. La centralità globale: la città nella rete mondiale. In: GOTTMANN, J. e MUSCARÁ, C. (Orgs.). La città prossima ventura. Roma-Bari: Laterza, 1991. p.5-21.

GOTTMANN, Jean. Il significato del territorio. Roma: Nexta Books, 2005.

MUSCARÀ, Calogero. La geografia dello sviluppo. Sviluppo industriale e politica geografica nell'Italia del secondo dopoguerra. Milano: Edizioni di Comunità, 1967.

MUSCARÀ, Calogero. La società sradicata. Saggi sulla geografia dell'Italia attuale. Milano: Angeli, 1976.

MUSCARÀ, Calogero. Reflections on Gottmann's thought. Ekistics, volume 70, n.418-419, 2003, Athens, p.10-12.

MUSCARÀ, Calogero. From Gottmann to Gottmann: testing a geographical theory. Ekistics, volume 70, n.418419, 2003a, Athens, p.60-63.

MUSCARÀ, Luca. The long road to Megalopolis. Ekistics, volume 70, n.418-419, 2003, Athens, p.23-35.

MUSCARÀ, Luca. The complete bibliography of Jean Gottmann. Ekistics, volume 70, n.418-419, 2003a, Athens, p.111-119.

MUSCARÀ, Luca. Introduzione. In: GOTTMANN, J. Il significato del territorio. Roma: Nexta Books, 2005, p.V-XII. 
MUSCARÀ, Luca. La strada di Gottmann. Tra universalismi della storia e particolarismi della geografia. Roma: Nexta Books, 2005a.

QUAINI, Massimo. Costruire 'geostorie' - un programma di ricerca per i giovani geografi. Geostorie, Roma, anno 11, n.1, 2003, p.3-15.

QUAINI, Massimo. Paesaggio, ambiente e geografia. Una vita per una geografia attiva. Giornata di studi in memoria di Giuseppe Barbieri, Firenze, 2005.

RAFFESTIN, Claude e TURCO, Angelo. Epistemologia della geografia umana. In: BAILLY, A. (Org.). I concetti della geografia umana. Bologna: Pàtron, 1989. p.15-25.

SAQUET, Marcos. Proposições para estudos territoriais. Geographia, Rio de Janeiro, n.15, 2006, p.71-85.

SAQUET, Marcos. Abordagens e concepções de território. São Paulo: Expressão Popular, 2007.

Recebido em abril de 2009

Aceito em agosto de 2009 